\title{
Aesthetic Research of Colors in Chinese Folk Art Yejun $\mathrm{Fu}$ \\ Southwest University for Nationalities, Chengdu Sichuan, 610041, China
}

\author{
Key words: Folk, Fine arts, Colors, Aesthetic, Research.
}

\begin{abstract}
Chinese folk art is a traditional ethnic culture formed through long-time historical sedimentation. Since a relatively complete color system has been developed in folk art, and distinct color esthetic characteristics have been formed, numerous researchers have been attracted to focus on the topic of aesthetic research of colors in Chinese folk art. From another point of view, aesthetic research of colors in folk art is of great significance to the exploration of the artistic value of today's society. The unique Chinese traditional culture showed in the colors of fine arts doesn't only contain profound folk spirit and has deep historical and cultural value, but also can enlighten color esthetic in artistic design and guide realistic design that show the unique artistic charm. In this paper, the writer has roughly introduced the process that the colors in Chinese folk art came into being, the concept of the colors in Chinese folk art, and the contents of the colors of fine arts, and interpreted the basic characteristics of colors in folk art from the aspects of subjectivity, stylization, regionalism, and symbolism to analyze and summarize its aesthetic value, with an aim to providing reference for future research on Chinese traditional culture.
\end{abstract}

\section{Introduction}

The colors in Chinese folk art have rich aesthetic features with Chinese characteristics. Through long-term color evolvement and development, and under the edification of traditional ideology and traditional culture, the concrete art modeling and forms reflected by the colors in folk art actually are the historical refraction of the folk spirit of a certain period of Chinese society, of great social meaning [1]. In other words, the colors in folk art have profound historical and cultural research significance while showing specific aesthetic value. Specifically, the color aesthetics of fine arts is one of the carriers of Chinese traditional culture and art. Not only the national psychology, folklore ideal, folk spirit and traditional philosophies contained in it have influenced the basic constitution of artistic colors, but also its complete color system and color aesthetic features with Chinese characteristics are of high application value and guiding significance to modern artistic design [2]. In view of this, this paper will focus on "aesthetic research of colors in Chinese folk art", as below.

\section{Overview of Chinese Folk Art}

\section{Concept}

Chinese folk art mainly refers to aesthetic art developed in folk in China, of which the main aesthetic contents reflect the main contents of people's daily life. In other words, Chinese folk art also can be interpreted as the embodiment of the traditional ideology, culture and aesthetic idea of Chinese working people, belonging to the scope of life activity art. In the Dictionary of Chinese Folk Art, related research scholars defined Chinese folk art as: an art form with diversified characteristics created by Chinese working people to meet related aesthetic needs in life and work in the long historical developing process [3]. Meanwhile, since folk art is closely linked with people's real life, the development and evolution of contents of folk art in different aspects, including drawing, 
sculpture, architectural style and craft all proceed to meet the concrete needs of working people in daily life, such as creation, application, and appreciation [4]. From the perspective of modern art, Chinese folk art has summarized the manners and customs of working people of all ethnic groups in China, so that their aesthetic ideas and ideological characteristics can be embodied in diversified art forms. Therefore, Chinese folk art has a great enlightening and guiding significance to both historical research of folk art and realistic guiding with the rich Chinese cultures contained in it.

\section{Classification of Chinese Folk Art}

As stated above, the development of Chinese folk art originated from the creation of working people in life. Since China is a country with an ancient civilization vast in territory and diversified in ethnic group, Chinese folk art, according to different regions and ethnic groups and from different angles, can be classified as below. (1) By the practical purpose of fine arts, its art form is mainly to reflect festive air, enrich the art atmosphere and render festivals in real life; meet the basic necessities of life (food, clothing, shelter and means of traveling) of people; express or vent personal emotions or represent true stories or deeds, etc. [5]. (2) By the categories of folk art, the art forms also can be summarized according to the classification method of Chinese traditional customs. For example, the couplets for birthday congratulations, bottom drawer and toys for children can be included in the customs and manners; costume, embroidery, architectural furniture and ceramics are the embodiment of art aesthetics in the basic necessities of life of people; colored-lantern making, New Year pictures, and paper-cut and other art forms for rendering festive air can be included in seasonal occasion needs; decorations for temple, myth prints and masks are the embodiment of folk beliefs. On the whole, traditional Chinese fine arts can be classified into three categories, i.e. folk painting, folk sculpture and folk handicraft [6].

\section{Generation of Colors in Chinese Folk Art}

Chinese folk art is an embodiment of art forms, and the development of the colors of fine arts also directly reflects the evolution of Chinese folk aesthetic art to a certain extent. Dating back people's perception of colors, the colors in Chinese folk art have developed from original and single color perception to the color perception of colorful decoration. For original and single color perception, the perception of white, black and red in different regions is of certain similarity, which had been being taken as the main presentation means of colors for a long time in follow-up color development [7]. The process of developing from single color to multi-colors is closely linked with the progress of productive labor force of working people for a long time. With respect to the transition from single color to multiple colors from the perspective of historical and humanistic development, a deeper meaning of color evolution can be extended. For example, during the Warring States Time, the colorful wall painting popular for a time was an importance embodiment of the development of colors in folk art. It was a slavery society period, the feudal superstition haunted at that time, and the theory of Yin and Yang and five elements emerged and became popular at that time too. The theory of Yin and Yang and five elements refers to that people combine five elements (metal, wood, water, fire and earth) with colors, symbolize five time points with seasons in correspondence with the five colors, and indicate five directions with the five elements. This result reflects the perception of the correlation between nature and life of people at that time, and marks that human's concept of five colors began to change into the expression of the correlation between the color aesthetics and subjective feeling and the time and space [8].

\section{Analysis of Aesthetic Characteristics of Colors in Chinese Folk Art}

\section{Subjective Aesthetic Characteristics}

Subjective aesthetic characteristics are mainly reflected in people's subjective feelings of aesthetics. Different from the rational and logic color exploration from original colors to conditional colors in the west, the colors in Chinese folk art focuses on the expression of integrity. People are good at visually 
presenting the themes they want to express with various color matches. Usually, people always give prominence to a certain essential color in expressing a theme, which has led to the practice that Chinese folk art ultimately aims to stimulate human's sense organs.

\section{Stylized Aesthetic Characteristics}

Since the development trend of Chinese folk art is from single color to multiple colors, then as to the actual application of the colors of fine arts, people will rationally match colors based on past experience. Thus, the inheritance-style art in folk undoubtedly has given the stylized aesthetic characteristics to the development of the colors of fine arts. In the thousands of years of evolution process of the colors of fine arts, some fixed color model with Chinese characteristics have been formed in the long history unconsciously. for example, according to the pithy formula for coloring clay figurine carrying on from generation to generation in Wuxi, "red is for showing charm, green for delicateness, white for purity, and pure colors for reflecting soul like paper", which indicates the stylized application of colors. From another point of view, the stylized aesthetic characteristics of the colors of fine arts also implies that the core of color development can be held even through historical, time and spatial aesthetic evolution, which has further formed the tenacious vitality with double characteristics of aesthetic classics in folk and philosophy, long-standing and youth.

\section{Regional Aesthetic Characteristics}

The expression of the colors in Chinese folk art is closely related to people's living habits, traditional concepts and folk cultures. Therefore, the application of colors of fine arts varies from region to region due to different customs and concepts of life, and has certain regional cultural characteristics, namely regional aesthetic characteristics. Meanwhile, it is because the colors of folk art have prominent regional characteristics that the diversified development of color aesthetics has been greatly promoted. For example, during the Republic of China era, the New Year pictures prevailing in the regions south of the Yangtze River were wood pictures, and mainly showed folktales or folk life, having a strong smell of local characteristics. As for the overall composition, various complicated colors were adopted, and red and purple often dominated, to show the happy atmosphere of the new year. Concerning New Year pictures prevailing in the north, such as the classic Yang warriors door-god pictures, brilliant yellow and cyan which is relatively bright were taken as the primary colors, which is the typical characteristic of New Year pictures in the north [10].

\section{Symbolic Aesthetic Characteristics}

From the aspect of modern color application, the colors of fine arts are grouped into warm colors and cool colors. That's to say, different colors will give different feelings and meanings to people. In the symbolic aesthetic characteristics of the colors of Chinese folk art, colors actually also are regarded as a symbol, standing for or representing a certain concept or thing. For example, the symbolic aesthetic characteristics of colors are reflected incisively and vividly in facial makeup of traditional Chinese drama. "Black stands for uprightness and boldness; red for loyalty and braveness; white for duplicity; yellow for violence; blue for wilderness; green fro chivalrousness; and pink for aging". For instance again, as to the masks of Tibetan opera, characters in masks in different colors have different rights and positions. Usually, red symbolizes power, so the paramount and powerful is designed to wear a red mask; green symbolizes life, so the character of mother is designed to wear a green mask; the sky blue symbolizes the god, and white stands for purity and kindness, and so on [1]1. It is thus clear that Chinese folk art can express people's thoughts and emotions via its symbolic meanings.

\section{Decorative Aesthetic Characteristics}

The aesthetic characteristics of Chinese folk colors have distinct features of oriental culture. That's to say, with the respect of color application and matching, people will pay more attention to the effect of visual pleasure while expressing subjective emotions and spirit. In decorative colors, the overall coordination between color tone and picture is regarded as important, which can be expressed according to your subjective feelings as much as you like. Take the example of Yangquan dough 
modeling in which red, green and other colors are boldly applied. This application of irregular colors seeming to be random can fully express the bright and joyful emotions. Decorative color matches have integrated the wisdoms in traditional fine art culture. Although the colors of Chinese folk art are not an artistic behavior, it shows the wish of the working people, and the decorative aesthetic characteristics of the colors of Chinese folk art also have been given profound connotations.

\section{Conceptual Aesthetic Characteristics}

The emergence and spread of folk art are mainly based on large-scale production activities. Therefore, as a traditional folk art form, Chinese folk art doesn't only refers to simple artistic creation, but also the outcome of the close integration of the constant development of mass aesthetic and people's life. This process of the colors of fine art deeply reflects the conceptual aesthetic characteristics of folk art. Meanwhile, fine art culture also has its own culture belief, namely traditional Chinese folk culture and customs and traditional beliefs of Chinese people. In the expressing process of the colors of fine arts, the cultural spirit, beliefs and concepts also have been fully reflected in various works themed by Chinese folk customs. On the whole, the distinct aesthetic characteristics and national sentiments reflected by Chinese folk art both are the embodiment of Chinese people's traditional conceptual aesthetics.

\section{Conclusion}

So far, the colors of folk art have had a complete color system, and distinct aesthetic characteristics. Besides, the unique traditional Chinese cultures reflected in the colors of fine arts don't only contain profound folk spirit, but also have deep historical and cultural value. According to the definition of Chinese folk art, folk art mainly refers to artistic art with distinctive diversified, regional, symbolic, decorative and conceptual aesthetic characteristics created by Chinese working people to meet related aesthetic needs in their life and work. The aesthetic characteristics of folk art together give rich folklore ideal and folk spirit to the colors of art. To sum up, aesthetic research of colors in Chinese folk art has great cultural exploration significance.

\section{Acknowledgement}

Project description: 2016 basic scientific research fund project of central higher education institutions (project No.: 2016SZYQN59).

\section{References}

[1] Zhao Long, The Beauty of Liu Zongyue's Craft: Seek the Value of Folk Art from the Aesthetics of Life, Journal of Changchun University (Social Sciences Edition), 2015 (04): 133-136.

[2] Liu Lu, Aesthetic Research of Colors in Chinese Folk Art, Literature Life (Trimonthly Publication), 2015 (03): 171-171.

[3] Deng Yanfeng, Focus on Civilization of Civilized Dunhuang-Aesthetic Research Based on Dunhuang Frescoes, Time Report, 2016 (04): 252-252.

[4] Cao Chengzhu, From Esthetic Custom to Discursive Practice: Body Consciousness inChinese Folk Songs and Ballads, Studies of Ethnic Literature, 2013 (04): 24-31.

[5] Tian Jiaqi, Aesthetic Characteristics of Traditional Decorative Painting, Popular Art, 2014 (19): 86-87.

[6] Song Fanghao, Painting and Life: Folklore Analysis of Paintings for Cooking Range in Jiaxing, Folklore Studies, 2016 (04): 129-135. 
[7] Han Xiao, Zhang Lin, Tang Sheng, et al, Conception of Applying Auspicious Patterns of Clay Sculpture in Fengxiang in Animation Art, Appreciation, 2015 (01): 135-135.

[8] Ma Fang, Fu Lu, Traditional Folk Toys-Design Aesthetic Research of Drum-shaped Rattle, Design, 2013 (08): 46-47.

[9] Zhong Xiaoyong, Aesthetic Research Perspective of Folk Music of Minorities in Dehong Prefecture of Yunnan from the Perspective of Anthropology, Folk Music, 2014 (02): 50-53.

[10]Cui Naidan, Brief Discussions on Steamed Twisted Roll, A Folk Art Form, Literature Life (Trimonthly Publication), 2013 (06): 133-133.

[11] Yan Jiansheng, Ritual Literature: Prototype Model of Folktale of the Yao People, Journal of North University of China (Social Sciences Edition), 2014 (05): 98-102. 